\title{
METODOLOGIA DA PESQUISA AMBIENTAL A PARTIR DA FENOMENOLOGIA DE MAURICE MERLAU-PONTY
}

Luiz Augusto Passos ${ }^{1}$

Resumo: O presente artigo pretende expor pontos centrais da concepção fenomenológica de Maurice Merleau-Ponty, e alguns gonzos que fundam o que se poderia chamar uma concepção filosófica com consequências teóricometodológicas para pesquisa. Corpo próprio, carnalidade, intencionalidade, quiasma, abrem um importante diálogo entre ciência e filosofia, contemplando uma longa interlocução com a neurociência, psicanálise, antropologia propondo a uma perspectiva positiva de educação ambiental dentro de uma radical interpenetração entre todos os seres animados e inanimados. Quebra-se, de maneira radical, todo antropocentrismo e retoma-se o sentido de animalidade que funda a rede da vida.

Palavras-chave: Merleau-Ponty. Educação Ambiental. Pesquisa em Fenomenologia.

\section{METHODOLOGY OF ENVIRONMENTAL RESEARCH FROM THE PHENOMENOLOGY OF MERLAU-PONTY}

Abstract: This article seeks to expose the central points of the phenomenological conception of Maurice Merleau-Ponty, and some hinges that underlie what might be called a philosophical concept with theoretical and methodological consequences for research. Oneself, carnality, intentionality, chiasm, open an important dialogue between science and philosophy, contemplating a long dialogue with neuroscience, psychoanalysis, anthropology, proposing a positive perspective of environmental education within a radical interpenetration of all animate and inanimate beings. Radically break up all anthropocentrism and resume the sense of animality that founds the way of life.

Keywords: Merleau-Ponty. Environmental Education. Phenomenology Merleaupontyana.

\section{METODOLOGÍA DE LA INVESTIGACIÓN AMBIENTAL POR LA FENOMENOLOGÍA DE MAURICE MERLEAU-PONTY}

Resumen: Este artículo busca exponer los puntos centrales de la concepción fenomenológica de Maurice Merleau-Ponty, y algunas articulaciones que subyacen a lo que podría llamarse un concepto filosófico con consecuencias teóricas y metodológicas para la investigación. Cuerpo propio, la carnalidad, la

\footnotetext{
1 Doutor em Educação Pública (UFMT) e em Educação: Currículo (PUCSP). Professor Associado Universidade Federal de Mato Grosso e do Programa de Pós Graduação Mestrado e Doutorado, coordenador do Grupo de Pesquisa Movimentos Sociais e Educação e do Grupo de Estudos Educação \& Merleau-Ponty. Cuiabá - MT; passospassos@gmail.com.br
} 
intencionalidad, el quiasmo abren un diálogo importante entre la ciencia y la filosofía, la contemplación de un largo diálogo con las neurociencias, el psicoanálisis, la antropología, proponiendo una perspectiva positiva de la educación ambiental dentro de una interpenetración radical de todos los seres animados e inanimados. Queda roto, radicalmente, todo antropocentrismo, y asumiese el sentido de la animalidad que fundó la red de la vida.

Palabras clave: Merleau-Ponty. Educación Ambiental. Investigación en Fenomenología.

\section{Introdução}

Há uma base de orientação teórico-metodológica com implicações nos procedimentos de pesquisa e em suas interpretações. Na fenomenologia a relação de tudo com tudo e todos e todas é considerada o centro de todas as articulações. A vida foi feita para comunicação. O corpo de/para expressão. A doença é a não comunicação. A interdição da palavra falante. A impossibilidade de encontrar a palavra que expresse o que se vive no âmago da experiência humana decreta a solidão, a perda dos laços e a morte: Só uma palavra me devora, aquela que meu coração não diz... ${ }^{2}$. A pesquisa é a procura de enxergar o invisível, os sentidos não expressos. Busca, também, da Palavra enunciadora, esfomeada por viver. A metodologia terá que seguir a vida.

$\mathrm{O}$ rigor, em pesquisa, tem sua origem primordial no procedimento justo e adequado, compatível, nos resultados, com a precisão necessária que não falsearia nem informações, resultados cálculos desejados, ensejando procedimentos que trouxessem uma aproximação capaz de patentear constâncias ou naturezas derivadas de certo objeto. Captando, por isso, de certa lógica inerente, mas velada em sua aparência e manifestação.

\section{Merleau-Ponty um filósofo voltado para o fenômeno.}

Merleau-Ponty não é um intelectual nem idealista, nem materialista, nem conformista, e diz, sempre, o porquê de suas peregrinações. Essa é a tarefa que ele nos propõe, um caminho mais longo. Desejamos dar a compreender em parte essa perspectiva filosófica, por nossa leitura de Merleau-Ponty; por seu intento teimoso de diálogo com os conceitos clássicos da filosofia, não destiná-los jamais ao lixo, revisando-os, menos à luz de pressupostos pensados, do que do chão da vida, do corpo que faz, pensa, sente e cria.

Fenomenologia é, sobretudo, a relação de mútuo encontro entre interessados de subsistirem pela relação. $O$ fenômeno se comunica em certas linguagens, que constituem signos, representações não completamente vazias ou neutras, nem isentas das experiências sensório-culturais, manifestação da complexidade - a linguagem como feitiçaria (WITTGENSTEIN,1979). Haverá, por isso, em seus resultados analíticos compreensivos dimensões próprias à cultura humana que não se distinguirão dele, que serão parte da sua apresentação, e derivam de nossas operações e interpretações, e somente por elas é possível uma tradução para o entendimento humano. Sintetizo, no

\footnotetext{
${ }^{2}$ Composição musical de Abel Silva.
} 
varejo: um fenômeno é a relação pulsante, de certa diafania entre a(s) coisa(s) e a gente que se geram e modificam nessa relação. E o resultado disso é um encontro entre duas dimensões reais, ativas, que se mudam uma a outra. Do fenômeno é também minha presença que deixa marcas nele, e minha vida jamais será a mesma depois que o encontrei, ele fará parte de mim. Estaremos anastomosados para todas as incursões que ele e eu viermos a fazer, enleados. Contudo, essa relação não é um dispositivo manipulado fruto de tecnologia, é como se fora amor à primeira vista, paixão, afeto no sentido grande - no sentido kantiano - ser afetado por, sem mediações.

Todo encontro revela que sequer encontrarei um mundo cuja conformação funciona como certa inteligibilidade que antes nele colocamos. Estarão diretamente vinculados à natureza originária dos entes percebidos, na sua condição de possibilidade de incorporar neles a mútua referência adquirida na relação interobjetiva-eintersubjetiva. Encontrarei, no mundo, aquilo que em grande parte coloquei nele. Não terei jamais do mundo sua essência, ele puro, isso é, ele mesmo por ele, sem mim. $\mathrm{O}$ contrário é verdadeiro.

\section{A fenomenologia no contexto das outras metodologias}

$\mathrm{Na}$ fenomenologia toda a incursão de querer cabalmente explicar o mundo, é inútil. Querer, definitivamente explica-lo - é loucura! Só no bojo de uma ideologia chamada cientificismo é possível afirmar essa possibilidade. Contradiz toda a ciência e o conhecimento real possível, vale a falsificabilidade contra os dogmas. Isto é, na ciência nenhuma verdade é isenta de poder ser falsa. Não vale o dogma. O conhecimento é inesgotável, porque nós e o mundo somos inesgotáveis. Não haverá nenhum conhecimento terminal. Se partíssemos do ponto de vista humano, - o da gente que em parte conhece -, cada vez que (re)fazemos um conhecimento, ele é fruto de recriação, nunca mais será o mesmo. Coincide com Paulo Freire, não somos seres históricos, somos seres historiadores (FREIRE,1968). Por isso, Paulo Freire inova a dialética hegeliana com sua formalização na tese, antítese e síntese. A síntese instável obtida nos processos, porque histórica e humana, nunca será o resultado da somatória do que estava antes na tese e na antítese obtida, porque estamos juntos na síntese, e, por nossa operatividade, alteramos o resultado. Há criação, jamais seremos repetidores, não é de nossa marca original.

Carnalidade e corpo próprio são duas expressões interdependentes e radicais de uma relação constitutiva e original, inseparáveis na fenomenologia de Merleau-Ponty. Há uma identidade resiliente, uma singularidade que aponta a que, a alteridade das coisas e dos outros, não sucumbem como se fora uma ameba sem forma definida e sem forma própria, incoercível, de ser. Testificam em carne $^{3}$ a impressão digital, os arranjos dos cromossomas, a digital de nosso polegar, a nossa pupila, que permanecem sendo nós, no abraço da carnalidade universal com todos os outros entes. Estes indícios biológicos que singularizam cada indivíduo só subsistem no ser, não são separáveis, livres de sociorrelações e mútuas referências que constituem cada um de seus elementos de maneira dinâmica e vital.

A fenomenologia deve suportar um diálogo com outras perspectivas epistemológicas que possuirão afinidades com as filosofias de implicações existencialistas, dialéticas, hermenêuticas, heurísticas que não mutilem pares dialéticos

\footnotetext{
${ }^{3}$ Carne, no contexto acima, colocamos em itálico, tomada no sentido cotidiano do termo, acerca da nossa materialidade biológica.
} 
ou polos de contradição que se apresentam à racionalidade linear, despida da complexidade e densidade dos fenômenos. E, portanto, afirmam a inter-relação entre objetividade e subjetividade, sem eliminação da relação dialética nem por uma pretensa sobredeterminação de um sobre o outro, nem por eliminações de qualquer uma delas, de forma que a epistemologia só afirmasse a partir da supressão do objeto sob a passividade do sujeito, o vice-versa, só a atividade constituidora do sujeito sob a passividade e inatividade do mundo e de seus opostos. O objeto está para um sujeito até por força da linguagem: ob-jactum o que está à frente jogado. À frente do quê? De um sub-jactum - isto é um sujeito, aquilo que sustenta, está no apoio dessa relação. Não há objeto sem sujeito, nem sujeito sem objeto. Por outro, sujeito e objetos são seres de razão, entes de relação, cuja realidade histórica e prática ou pragmática dizem de entes mutuamente relacionados e mutuamente em constituição um do outro, sem que sequer possa existir um sem o outro. Refere-se, portanto, a uma condição de toda a criatura. $\mathrm{O}$ mistério do nosso aparecimento biológico é, também, o mistério do nosso aparecimento como filo, e como seres reais: fomos precedidos por uma realidade que nos permitiu ser.

Sendo a fenomenologia interpretativa de fenômenos polissêmicos e densos, inesgotáveis, portanto, a partir de seus contextos próprios e dos lugares sociais e sentidos próprios construídos pela percepção de sujeitos universais, ela suscita relação com todos outros e outras, com tudo, sem que nenhum desses entes ou coisas perca sua singularidade. Não há qualquer contradição em que eu - o todo qualquer outro ser humano - seja, sempre, universal, enquanto gênero humano; particular ao mesmo tempo como sujeito de etnia, tribos, simultaneamente único e singular. Dimensões estas que não se excluem (GEERTZ, 1989). Particulares e singulares referenciados a um mundo cultural, a fenomenologia é um convite à interlocução de olhares, situados num historicidade dinâmica e complexa, que instiga a abertura de todos e todas às interpretações do mundo de outras e múltiplas perspectivas. Não se trata da buscar o oásis de uma síntese. Não existem sínteses! Sequer passam pela causação ideológica ou epistêmica, como encontros de racionalidade e conceitos pensados, que, nesse caso, nos interessam menos. Trata-se de que os entes que no SER se comunicam numa imbricação de origem. Cada corpo próprio - singular - está num emaranhado com outros corpos próprios, em uma intracorporalidade que a todos(as) precede. $\mathrm{O}$ mundo, também para Paulo Freire (1965), nos precede. Sem ciúmes ou apropriação da verdade e do conhecimento, mutuamente se reconhecem, como cocriadores, num compartilhamento de perspectivas de manifestações múltiplas de suas culturas e experiências, que, apenas quando existe o cuidado e o amor entre coisas e pessoas, é possível manter-se enleado, sem diluir-se.

A experiência de intercorporeidade é uma das experiências originárias da ontologia, da 'formação' do Eu e do Outro, ou seja, só se pode compreender o humano histórico-ontológico enquanto ser social. É nesta experiência intercorpórea que o mundo sensível tem o seu significado, tanto o mundo sensível natural quanto o artificialmente produzido pelos homens e mulheres: “... uma consciência não saberá encontrar nas coisas senão o que nelas pôs” (MERLEAU-PONTY, 2012, p. 233, grifos do autor).

O sentido se cria desta relação intercorpórea, que por sua vez se cria a relação intersubjetiva, ou seja, o sujeito é um campo de experiência (CABRAL, 2014, p.9) 
A fenomenologia de Maurice Merleau-Ponty nunca será uma filosofia idealista, em seus pressupostos teóricos. Ela bebe, sobretudo, no último Husserl, e encerra toda a possibilidade de ser positivista! Contudo, se houvesse um princípio que identificasse o ato mesmo de conhecimento, ela seria materialista em suas raízes sensistas e da corporalidade. Mas, - e há sempre um mas -, na fenomenologia, há de se ter todo o cuidado de não se poder, jamais, separar ou isolar uma interioridade imaterial arraigada no coração de toda a matéria. Isso não simplifica nada. Complica e implica. Razão pela qual toda a díade, toda polaridade dialética muda, para Merleau-Ponty, completamente de lugar. Há uma conexão: o quiasma. Quiasma é uma miscelânea biológica que põe coisas contrárias e/ou contraditórias em movimento único. Uma bifurcação, tipo: matéria e energia.

Merleau-Ponty é antirreducionista, não admite a desvinculação que é lugar comum do pensar da modernidade clássica, a Fenomenologia afirmará a indistinção relacional ontológica de que cada polo contrário da filosofia clássica, que gera a dialética dos contrários, com-preende que cada um deles é tão somente o lado avesso do outro ou de si. Eles se encontram, sempre, relacionáveis, e num emaranhado que precisa ser tratado como o outro lado do mesmo.

Vamos ao mais radical emaranhamento. Desde a "Fenomenologia da Percepção" até as últimas notas escritas por Merleau-Ponty no "Visível e o Invisível" não se poderá separar a fenomenologia - isto é, o que aparece do ser - daquilo que o ser é mesmo, isto é, de sua ontologia! Ambos são manifestações de regiões, correlacionadas até o fím, faces da mesma moeda. Portanto, aquilo que Filosofia vê com naturalidade, expresso por Platão que a aparência do ser engana e é irreal, é reinterpretado pela fenomenologia. Fenomenologia não se separa da ontologia. A briga eterna, expressa desde as primeiras páginas da "Fenomenologia da Percepção" de M. Ponty até as últimas páginas de "Signos" e do "Visível e Invisível" O filósofo se desvencilha do dualismo cartesiano.

A fenomenologia dialoga com os empiristas e com os idealistas. Possui um pé na ciência outro na filosofia. Não admite uma cesura nos conceitos de natureza e cultura, nem sujeito e objeto, nem causa e efeito! Também, não joga fora os conceitos da filosofia clássica para formar um aparato novo, considera a riqueza existente nessa tradição, mas redefine a grande maioria dos conceitos, voltando a um hiperdialética, continuando, de certa forma, o que foi interrompido pelo filósofo Descartes: a crítica da crítica. M. Ponty chama ainda de hiperdialética, superação da dialética dos contrários inconciliáveis. Menciona que os filósofos aderem a interacionismo entre sujeito e objeto, mas não raro, a maioria termina para conseguirem a síntese arrumada, ou só com o sujeito, e colocam o objeto fora, ou ficam só com o objeto e jogam o sujeito com a água do banho. É importante afirmar que os contrários coexistem, não devem ser negados com regiões de sua natureza ou essência, mas as reconhece como coexistentes no ente vivo, ou na vida viva, sem resolver a contradição por alinhamento, para salvar a razão. A fenomenologia merleaupontyana é uma dialética que não acredita em sínteses finais felizes, que servem para aplacar o pensamento e a angústia. Faz, como pretende Merleau-Ponty, um caminho mais longo, mais paciencioso. Nesse sentido, é uma filosofia que precisa aprender a ver o mundo com apoio da ciência e da filosofia, seja a filosofia sem a ciência, ou a ciências sem filosofia, diz Merleau-Ponty, serão cegas, não saberão do que falam. Uma sempre precisará da outra para alargar horizontes. 


\section{Visibilidade da ambiguidade dos fenômenos}

É importante ter presente que as aparentes aporias e contradições, que M. Ponty chama de ambiguidades, fazem parte do jeito das coisas ser. Isso também pertence ao nosso limite ontológico, de origem e fabricação e, sobretudo, de autofabricação de nós mesmos por nós.

Talvez, por último, a fenomenologia não é antimarxiana, Merleau-Ponty dialoga com Marx, possui textos clássicos dessa interlocução, e afirma que não se pode prescindir de Marx, não cabe - porém - na bitola, simplificadores de alguns marxismos de plantão ${ }^{4}$. Entre os quais, aqueles que pretendem certezas fechadas, pela objetificação dogmática dos saberes iluminados por uma ciência sem incertezas; pela naturalização e linearização-mecanicista da história, pelas subjugações estruturais da díade infraestrutura versus superestrutura, por um evolucionismo ascensional que reedita um monismo que (des)reconhece diferenças e as lineariza; pelo salto de um desfechosíntese - apaziguador - que quebra a própria lei do motor da história e a conclui por um salto divino ex machina e cessa a lei da dialética por um paraíso sem contradições; ou quando pretende substituir individualidades por suas funções economicistas úteis universalizadas; pela pretensa superposição de outras dimensões que fizeram Marx, no seu tempo, ainda que rindo, dizer, segundo Hegel: "Eu não sou marxista!"5

\section{O mundo da vida}

Compreender o sentido de uma filosofia que perscruta as origens é necessário saber como a vida se cria, e compreendê-la como comunicação. O corpo se constitui como materialização do necessário desejo de expressão e comunicação, já presente na animalidade que nos precede. Nascemos de uma relação entre um homem e uma mulher. Eles nos anteciparam. Escolheram por nós e fizeram-nos, com maior ou menor consciência, essa vida de ambiguidades e contingências. Minha presença no mundo, intencionada ou não, se deu. E a relação exprime caroço mais central do mistério da criação. Buber (2009, p.26) o afirma de maneira radical: "No começo era a relação".

Toda relação é reciprocidade criativa ou o seu contrário, aquilo que a embarga, a sufoca e a faz morrer, mas essas dimensões não se encontram em nós em limites discerníveis: somos-um-e-outro - ambiguidade. O itinerário original busca viver e fazer viver; mas também gera o ato de poder não doar, de suspender a irretorquível vontade do se continuar sendo, expresso na direção do impulso de vida e morte. A grande

\footnotetext{
${ }^{4}$ Veja, em Vídeos merleaupontyanos no site: <http://radio.luizaugustopassos.com.br/>, o último bloco da palestra de abertura de Creuza Capalbo, enfocando o tema da fenomenologia e do marxismo (acessado em 23/04/2014).

${ }^{5}$ Quando Marx disse para Engels, ao aparecer um par de vezes entre 1880 e 1881, já em sua velhice, "eu não sou marxista", estava protestando contra a leitura e aproveitamento que faziam de sua obra econômica e política pessoas como os "possibilistas" e guesdistas franceses, intelectuais e estudantes do partido operário alemão e "amigos" russos que interpretavam mecanicamente $O$ Capital. Pelo o que se sabe desse momento, por Engels, Marx disse aquilo rindo. Porém, além da brincadeira, resta um assunto sério: Marx não gostava nada do que começava a navegar com o nome de marxismo. (...) Da séria brincadeira do velho Marx somente podem deduzir-se razoavelmente duas coisas. Primeira: que ao dizer "eu não sou marxista" o autor da frase não pretendia desqualificar a totalidade de seus seguidores nem, menos ainda, renunciar às suas ideias ou influir em outros. Segunda: que para ler bem Marx não é necessário ser marxista. Quem queira sê-lo hoje terá que sê-lo, como pretendia o dramaturgo alemão Heine Müller, necessariamente por comparação com outras coisas. E com seus próprios argumentos (BUEY, 2007, p.8-9).
} 
doença, contudo, é a não comunicação. A interdição da palavra falante. O silenciamento imposto. Somos Palavra em carne que procura formas de expressão e comunicação. A comunicação é o ato contínuo de se poder viver e expressar, e, por isso, também movimento de Cura, cuidado e de saúde. Educar é curar, nos sentido do cuidado com a expressão do ser que nasce para viver e crescer. $\mathrm{O}$ chamado ontológico a ser mais, no caso das pessoas: a ser Mais Gente (FREIRE, 2000).

A impossibilidade de encontrar a palavra que expresse totalmente o que se vive no âmago da experiência de homens e mulheres é, também, uma condição humana, dado que não podemos colocar num símbolo, numa dicção, aquilo que exprime a totalidade do ser, em nós. Toda expressão é também inconclusa, e, por isso, inesgotável. A solidão pode resultar na perda dos laços. A solidão também permite positividade, de realizar um mergulho profundo em nosso interior, e esse mergulho não nos conduz ao isolamento, à negação do impulso de viver, mas pode gerar, frequentemente, o que chamarei de transcendência para baixo, o encontro radical com a carne original do ser, que nos universaliza no mais íntimo da matéria, do barro irradiante que nos constitui. E quando falo de barro irradiante, falo do fato da ciência, energia e material são dimensões da mesma natureza quiasmática ${ }^{6}$, uma se transforma em outra e volta, com recursividade, a ser o que era, sem deixar de perder o que antes tinha sido. A fenomenologia busca essa transcendência, isto é, o ato de poder ter acesso ao que está fora de nós, e que acaba descobrindo-o dentro. Diz Chauí (2002, p.67). "Há a carne do corpo e a do mundo; há em cada um deles a interioridade que se propaga para o outro numa reversibilidade permanente".

"O mundo está dentro e eu estou fora" - escreve Merleau-Ponty em "Signos" (1991, p.12). E a consciência é o lugar da dupla transitividade: é consciência de alguma coisa e consciência para um certo fim.

Roubando de Agostinho: Intimo intimeor- o mais íntimo do íntimo. E, não se precisa pensar, necessariamente, em um Deus. Não há qualquer metodologia destituída do essencial, a presença que se ancora no lugar mesmo da vivência corporal, compreendido o corpo como o aparecimento da pessoa em espaço e tempo ao mundo, no mundo e para o mundo. Presença é mais do que presença meramente física. Toda pesquisa é a imantação atenta e intencional dessa imersão, explicitada em linguagem comunicativa, que media essa vivência compartilhada com os outros eus que vivem no universo, nas teias do mundo, que nos fazem diversos e semelhantes. Para Creusa Capalbo (2004, p.62), "a linguagem representa a forma mais alta da condição humana: sua capacidade de simbolizar".

Pelo símbolo encarnado e polissêmico, o sujeito relaciona-se com o mundo sensível, com o outro e consigo. Encarnado em situações espaço-temporais concretas, vivenciadas pelo corpo-próprio. É na linguagem, enquanto manifestação ontológica, que o signo, para Merleau-Ponty (2012, p.67-68), "aproxima-se tanto quanto quisermos da significação tão logo o considero disposto a funcionar na linguagem viva". E, como essas experiências perceptivas nunca esvaziam o seu significado, possuindo sempre outros significados, momentaneamente, não percebidos pela intencionalidade do sujeito de relação (CABRAL, 2014, p.4).

\footnotetext{
${ }^{6}$ Quiasma, palavra que vem da biologia, é o que expressa um entrelaçamento de dimensões contraditórias em nós, que nos singulariza como 'corpo próprio'-único - e ao mesmo tempo nos universaliza na criaturidade universal, que em Merleau-Ponty se chama 'carnalidade'. Talvez a metáfora de Clifford Geertz expressa isso, quando afirma que o que existe de mais universal em cada pessoa, é que todos somos diferentes.
} 
Somos interação, intracorporalidade, meu corpo não termina na minha pele. Não tem limites. Trocas que geram fios de rede, que se tramam e se entrecruzam na perspectiva de uma tecedura que emerge do desejo de ser. Quando comprimo a mão de alguém em minha mão, minha percepção me diz, em pouco tempo, eu não sei de fato onde começo e onde termino. Quando divago dentro das águas do mar, não tenho fronteiras. Por isso, a fenomenologia insiste que somente o tato me proporciona meu limite e o limite do outro(a). Somente na relação direta com outro corpo, pelo tato sei da minha existência como corpo. Qualquer outro sentido não poderá me trazer essa certeza. A fenomenologia é, a rigor, encontro intencional com tudo, todos e todas as coisas. Expressão genética de querer viver sempre mais aberto à relação com a alteridade e a diferença; o corpo tem fome da diferença para se abrir ao único caminho: o amor que gera e faz viver, sem sufocar ou suprimir.

Desde Husserl, houve desejo de se desfazer da existência ontológica de díades apartadas, isto é dos polos entre o fenômeno exterior e sua essência, ou dito de outra forma, não haveria uma dissociação possível entre uma fenomenologia e uma ontologia. Ouçamos Capalbo $(2008,19 ; 20)$ :

\footnotetext{
Perceber não é receber sensações da psique, Não nos é possível separar fenômeno da coisa em si. O fenômeno é conhecido diretamente sem intermediários, ele é objeto de uma intuição originariamente doadora. (...) A visão das essências é uma intuição, isto é, um ato de conhecimento direto, sem intermediários, que nos põe em presença, num face-a-face do objeto "em pessoa".

"O ser, enquanto corpo-próprio, é o ser que percebe, que sente a si mesmo, o outro e as coisas. É essa carnalidade do Ser que condiciona a comunicação sempre aberta e contínua - do corpo-próprio com o mundo sensível e do mundo sensível com o corpo-próprio, formando, assim, uma consciência encarnada. Como afirma Merleau-Ponty (2011, p.350-351): "minha percepção não se dirige a um conteúdo de consciência: ela se dirige ao cinzeiro mesmo" (2011, p. 350-351)." (CABRAL, 2014, p.7).
}

A diferença ontológica que nos funda é a mesma que funda os objetos, um estofo comum que circula em nós, mundo e sujeito ambos referidos um ao outro.

Merleau-Ponty insiste que, há um estofo do mundo compartilhado por nós, e que se estende a nós, e a recíproca é verdadeira. Há uma mútua constituição de uma carnalidade comum, que não nos permite experimentar a exterioridade hegeliana, da qual estamos em um fora absoluto, negado em essência - como trevas exteriores: estamos sendo! Não há, por isso, uma alteridade ou outridade ao qual o meu eu não se refira.

\section{Educação ambiental como impulso ontológico radical que emerge da falta de ser}

Aqui, nos interessa perguntar: em que sentido o conhecimento filosófico merleaupontyano funda e radicaliza uma ética e uma práxis importantíssima para a educação ambiental? Ela já não é uma sensibilização de compadecimento ou conversão afetiva por uma bandeira exterior, nem uma educação da percepção poética. Ela é condição, não enxerto nem derivativo contingente e relativo, mas expressão em corpo próprio de uma inerência de impulso da nossa condição ontológica e política. 
Essa relação com o/a(s) outro(a)s implica, de nossa parte, numa partilha de destinos históricos, somos um na carnalidade do ser. Somos, no sentido radical, uma comunidade de origem (ontológica) destino não teleológico, mas de implicação de mim no outro e do outro de mim. Através do qual tudo o que ocorra a qualquer um(a) outro(a), que compartilha do estofo do mundo e da matéria, diz respeito, também, ao meu próprio destino no destino consorciado. Mas, é mais que isso. Tudo o que diz respeito aos animais, às árvores, à terra, diz respeito à minha própria vida, inseparável desta cathexys $^{7}$ com tudo o que em meu corpo próprio, não tenho e não sou como falta demandante que grita. Tudo é, também, comum. Eu não tenho limite fechado na extensão do meu corpo, ele está além de mim. Isso diz respeito também à condição planetária. Importante, porém, é que o que me faz ser de desejo é a falta... Falta de ser. Nesse preciso sentido, a fenomenologia não tem esse movimento de fome de ser como virtude, mas como necessidade do vazio do ser que sou. Vamos a Merleau-Ponty: da modernidade clássica, da filosofia de plantão, lidar com a diferença, com a natureza, com concepções divergentes e apostar em certo rigor.

\begin{abstract}
Seja o isto que está sob meus olhos e que parece obstruir com sua massa o vazio que sou. Na realidade, este copo, esta mesa, este quarto não podem estar-me presentes sensivelmente a não ser que nada me separe deles, que eu esteja neles e não em mim, em minhas representações ou pensamentos, que eu seja nada. No entanto, diremos nós, enquanto tenho isto diante de mim, não sou um nada absoluto, sou um nada determinado: nem este copo, nem esta mesa, nem este quarto; meu vazio não é qualquer um, e, nessa medida, ao menos, o meu nada é entulhado ou anulado. (...) Uma negação efetiva ou original deve trazer nela mesma o que nega, deve ser ativamente negação de si mesma: "Na medida (...) em que o Ser a quem falta... não é o que lhe falta." apreendemos nele uma negação. (...) Seu fundamento reside na necessidade de o Ser a quem falta... ser o que lhe falta. É na globalização do mesmo movimento que o nada se cava e se enche. Uma filosofia que pensa verdadeiramente a negação, isto é, que a pensa como o-que-não-é-totalmente, é também uma filosofia do Ser. ${ }^{8 *}$ (MERLEAU-PONTY, 2012, p. 60-61).
\end{abstract}

A fenomenologia concebe o ser humano como inacabado, por isso não subsistirá sem a relação com todos os outros seres, que lhe tocam a pele e o coração. Ouvi em uma conferência no Fórum Social Mundial, Gustavo Gutierrez teólogo da libertação, dizia no Fórum Mundial, evocando um poeta: "O que existe de mais profundo na pessoa humana é a pele! Ela é a expressão pública ex-posta ${ }^{9}$ da nossa interioridade".

E, desde a fenomenologia de Husserl, Heidegger, Levinas, Hannah Arendt e Merleau-Ponty, é o tato o único sentido, já o dissemos, que assegura a existência dos corpos dos outros, nenhum outro sentido é capaz de fazê-lo, sem que vivêssemos de uma crença metafísica incapaz de conferir a experiência daquilo que é, também, a expressão mais singular de nosso corpo em comunicação com outros corpos, no mundo. O corpo é o partilhamento, é a comunhão, é publicização do que me é mais pessoal, e que permite na experiência do carinho, do sexo, da comensalidade, do calor do outro, a aferição de meu próprio corpo, de que não sou apenas uma ideia vazia ultrafísica, com substancialidade. De forma que a minha corporeidade íntima e própria possa expressar

\footnotetext{
${ }^{7}$ Expressão de Freud que diz respeito à união entre a libido (cargas de energia) e o objeto que recebe essas cargas, de forma que se tornem um.

${ }^{8}$ À margem do texto original de Merleau-Ponty se encontra a anotação: o destino do nada e do ser são o mesmo, se pensar bem o nada.

${ }^{9}$ Ex-posta: colocada (posta) para fora (ex).
} 
no olhar, no ouvir, no sentir afetivo uma carnalidade oferente e ofertante de cumplicidade telúrica com os muitos mundos que me recobrem. Trata-se, por isso, de encontrar o nosso sentido, no sentido de cuidado de todos os outros entes e criaturas.

\begin{abstract}
O que trago de novo ao problema do mesmo e do outro? Isto: que o mesmo seja o outro de outro, e a identidade diferença de diferença - isso 1) não realiza superação, dialética, no sentido hegeliano 2) realiza-se no mesmo lugar, por imbricação, espessura, espacialidade (MERLEAU-PONTY, 2012, p. 237$)^{10}$.
\end{abstract}

Não poderei, pois, nesta condição de historicidade, de situação espaço-temporal frustrar-me de tecer um elo, que para além do meu próprio corpo, possa através da carnalidade que nos une promover certa intracorporalidade que permita ser um elo de uma grande rede de vida, no planeta e no universo. Carnalidade que expresse essa dimensão comunicativa sem fronteiras, que abraça não apenas o mundo humano, mas todo o mundo inumano que nos toma.

\title{
7. Um diálogo como filósofo Fabio Di Clemente
}

Em recente conversa com o Filósofo Fabio Di Clemente (UFES) ele me dizia, que de Merleau-Ponty fica claro que não seria possível imaginar que a forma com que olhamos, não compartilhasse do olhar de um urso que está vivo em nós; que os cheiros que sentimos não compartilhassem da certa acuidade retida dos lobos e cães; que sequer poderíamos compreender que todas as nossas células não guardassem de certa memória de uma intensa peregrinação que se fez em nossa espécie. Nossas vidas não nos pertencem inteiramente. Elas são frutos de uma longa parição de um Universo que se expande e contrai, e do qual, magnificamente lembra (MORIN, 2001), que nossos corpos compartilham com a poeira das estrelas, mas me pertence também a mim, como se fora uma espécie que pudesse sobreviver sozinha e, inclusive, que se considerasse como o topo de matéria com interioridade, cujo cérebro - imaginária $\mathrm{e}$ cientificistamente - pudesse ser inteiramente separado do corpo com um todo, funcionando dentro de uma perspectiva epistemológica sem sua relação com o corpo. Não há, dizem, também, Deleuze (1997) e Merleau-Ponty (1961), em momento algum, um órgão epistêmico que possa funcionar destituído de sua relação no conjunto inteiro de um corpo. É essa conexão de tudo com tudo, biológica, neurológica, circulatória, psíquica e anímica que me permite que todo o corpo seja efetivamente o lugar de conhecimento.

Não há qualquer razão que possa negar a vida selvagem em mim, mas também a conexão com todos os recursos minerais, orgânicos e de teia nas energias que me universalizam e me particularizam, singularizados por mim-com. Como compreender senão como estranha a arrogância e etnocentrismo, querer erigir para nós, um altar por sobre todas as coisas, como se fôramos capazes de viver tal qual estamos sendo, destituídos delas? Como não compreender que somos, como diz Merleau-Ponty (1961), os mais desprotegidos de todas as espécies, mas também aqueles que, em muito pouco tempo, encontram em si os caminhos de uma peregrinação de todos os outros seres em nós, e que nos permite encontrar um caminho inédito e pessoal, trilhando pegadas a

\footnotetext{
${ }^{10}$ Este texto é esquemático. Trata-se das anotações de Diário que Merleau-Ponty, nominado após de Visível e Invisível, no qual, dia após dia, escreve como se conversasse consigo mesmo, procurando certa justeza filosófica na linguagem.
} 
partir da nossa própria materialidade amorosa que se move para o gozo de viver em comunhão?

É fundamental, na pesquisa fenomenológica, compreender uma das dimensões do conceito de estrutura em M. Ponty. Ela aparece de forma polissêmica, por vezes como uma estrutura que diz respeito a alguns espaços que compreendem pontos de chegada ou de partidas nos seres humanos, e diz ele que "indica um caminho fora da correlação sujeito-objeto que domina a filosofia de Descartes a Hegel" (MERLEAUPONTY, 1991, p.155). E, portanto, que possuam certo sentido parecido com um dispositivo ligado à espécie humana que permite alguns passeios por caminhos não tão desconhecidos. Mas, nas obras últimas de Merleau-Ponty, ele menciona com clareza uma estrutura que se desprega completamente do modelo coisificado, ou de suportes prontos com capacidades intrínsecas de repetir coisas mecânicas em todas as pessoas do universo, mas como um processo dinâmico a cada corpo próprio que em determinados momentos coincidem com algumas reiterações que exprimem, naquele conjunto de corpos próprios, sentidos que se conjugam num todo conhecido.

Não estaremos isentos, em momento algum, daquilo que fere a vida em qualquer lugar do planeta, isso nos diz respeito, e nos inclui. E, nesse sentido há uma ética e um direito que emerge de uma comunhão plena das coisas com a gente. Não é apenas em sentido moral que nos ocorre como uma implicação, mas se trata de um fenômeno da sinergia de toda a matéria que nunca é destituída de uma interioridade que se comunica, por autopoiésis ${ }^{11}$. Isto é, uma dimensão em que a Vida, no seu processamento incessante, desvela a nós como caminho a ser perseguido de concertação de ações e compromissos que a todos nos amarrem em uma perspectiva ético-política que funda nossa possibilidade de viver na convivialidade.

A fenomenologia merleaupontyana não poderá conter qualquer cisão entre sujeito e objeto, nem se aterá a eles. Há um fundamento genealógico e ontológico nisso. Merleau-Ponty não poderá conceber que as categorias sujeito e objeto possam ser consideradas como seres, ou entes, que subsistam como coisas em si mesmas, isto é, como coisa autônomas; serão interdependentes uma da outra e de um corpo próprio histórico. (HUSSERL, 1996) aponta muito antes de Merleau-Ponty, e já a partir de Brentano, que sujeito e objeto só existem correlativamente um ao outro. Semanticamente, sujeito deriva da expressão sub jactum, isso é, o que está suposto como base, como se estivesse permitindo, por baixo, o apoio ou chão que suportaria como fundamento a ação de um outro, na condição de ob jactum, isso é aquilo o que estaria jogado ou lançado (jactum) à frente de... um sujeito. Trata-se de uma terminologia descritiva da existência de uma relação, na qual há algo jogado à frente de um outro algo (relacional) que sustentaria essa relação (subjectum). Essa relação é meramente nominal, relacional, posto que ela enquanto relação-presença constituiria, ela mesma, uma dependência da existência do outro, fora de si. Ela inexistiria, ontologicamente, em filosofia, isto é, como coisas reais. Não existiria sujeito sem objeto e objeto sem sujeito. Sequer se pode dizer que algo constitui seu ser de objeto, ou seu ser de sujeito, pois se trata, apenas da denominação relacional, aquilo que a filosofia chama de ens rationis... isto é, só existem como entes de razão, só no pensamento. Não são coisas reais, vivas, que se possa pegar, tocar, ou tenham extensão. As filosofias anteriores se preocuparam em materializar, ou dar substância a essas relações, elas terminaram sendo reificadas, virando um aparato estrutural, não apenas formal, mas

${ }^{11}$ Aquilo que se cria, no sentido de arte, a si próprio. 
material, no sentido aristotélico, nos habitam sem existirem. E, é claro que há um peso distinto entre o que está como sujeito (fundamento) e o que está à frente de. Daqui se originou, na filosofia moderna, as posições sujeito versus objeto, mas também o debate infinito de quem domina e determina quem. Concebe-se previamente a relação como "gangorra", ou a objetividade pereceria no encontro com uma subjetividade vencedora no idealismo; ou, de uma subjetividade esvaziada frente a uma objetividade vencedora no objetivismo. E reporíamos a questão de Enrique Dussel (2000), uma sociedade que não pode pensar diferenças a partir de sua colaboração e complementaridade, acaba concebendo erroneamente a política como forma sistemática de dominação.

Fique, pois, claro, que a fenomenologia de Merleau-Ponty considera falso problema a pretensa disjunção entre objetividade e subjetividade; mais, de uma continuidade pouco crítica do ponto de vista filosófico de reificar pretensos sujeitos e objetos, e expor em arranjos postos em forma de estruturas. A fenomenologia não reifica objetos nem sujeitos. Dirá que existirão em relação. E que sem um, ou outro, ditos sozinhos, inexistirão. Isso implica que objetividade e subjetividade se põem, ambas, na relação. E, que há momentos em que a subjetividade e objetividade podem se superpor ou trocarem sua posição relacional. Nenhum ente, contudo, vale para animados e inanimados, pode ser objeto de. Ou seja, em que ele perca sua condição de também ser sujeito na relação. Nesse sentido, toda a relação objetificada mostra uma relação de violência: em Buber: Eu-Isso! (BUBER, 2009). Nesse sentido, o capitalismo como forma política sempre se caracterizará como uma monstruosidade. E, portanto, como a destruição dos seres humanos e de todas as coisas que perdem sua natureza também relacional e se tornam recursos, cujo fim está alienado delas mesmas, o que traduz o uso instrumental ou ferramental, como coisa, como mediação e não como tendo por si mesmo um sentido e valor intrínseco.

\section{A fenomenologia como provocação às grandes lutas dos oprimidos}

Merleau-Ponty (2011) alerta de que há uma relação circular entre eu-outromundo vivido na temporalidade, na espacialidade e na sexualidade que não são dimensões exteriores do ser, somos o Tempo, somos o Espaço e somos nossa Sexualidade (PASSOS. 2005). Nessa condição somos Relação que não tem começo nem fim, e possuirá uma dinâmica de mútua circularidade virtuosa. E, essa dignidade sustentaria o ciclo de vida. Daqui deriva uma ética e uma política. E, nesse preciso sentido não se poderá afastar uma inteligência dos processos ambientais, mas incluem também um conjunto de ações específicas, e inseridas no marco histórico das lutas, como uma pedra fundamental de princípio ético que não admite qualquer relativismo. Essa análise compreensiva da filosofia não é relativista; ela está na condição do que a filosofia sempre chamou de um princípio ético absoluto, em frente ao qual não se poderia optar por uma direção que lhe seja oposta. No caso, a vida como princípio ético absoluto, dado que não podemos cria-la. De sorte que, há sim uma ética voltada a perspectivas que implicam sempre não apenas a vida, mas a mais vida.

Ora, não há, contudo, no ser humano aberto à sua própria artesania, cujo destino diz respeito a cada qual, poder ser abandonado à nudez com que ele próprio nasce. Tampouco é possível, do ponto de vista ético, fazê-lo por uma artesania exterior, que queira nele reproduzir modelos vigentes ou usá-lo como para... E, sobretudo o risco de querermos fazer do outro nossa imagem e semelhança. Sobretudo porque, na analogia aceita de que somos Palavra de Deus, a semelhança a Ele implica em que, semelhantes a 
Deus o estatuto nosso é a da plena liberdade absoluta, para poder ser o que Ele é. Não permitiria reproduzir nas pessoas modelos estabelecidos por qualquer cultura que lhe implicasse na despotencialização das pessoas, que implicaria a despotencialização de tudo e todos(as). De sorte que a vida só, somente ela, à sua própria direção interna ${ }^{12}$, que funda também as possibilidades criativas de expressão e manutenção externa, terá que descobrir os caminhos em si própria, no diálogo com o meio, e, não terá receitas.

Nesse sentido, toda a imposição é um ato de violência sobre um corpo próprio que sempre terá todo direito à sua autonomia. A autonomia das pessoas tem sido, também, matéria de processos educacionais, porque a cultura tem tido uma direção contrária. O Poder dominante, em suas múltiplas formas, tem reproduzido um modelo de um ser humano-padrão. Thomas Merton (1961) dizia em certo texto lido por mim, em minha adolescência: "Todas as pessoas nascem diferentes, e a maioria termina como cópia!" É uma denúncia dos processos colonizadores das individualidades com vistas a um projeto homogeneizador que nega os direitos das pessoas poderem ser o que elas são. A autonomia não será, nunca, em princípio, um caminho individualista, pois o crescimento das pessoas, livremente desenvolvendo seu corpo na direção do seu melhor crescimento, também será a condição da melhor cidadania, da melhor participação e contribuição com a comunhão. Desenvolverá sua personalização no carinho, no apoio, na maternagem recebida, e reaprenderá a importância de convivialidade que o caracteriza de forma ontológica como elemento central de prazer. Claro está que a dimensão ética não tem previamente nada que conduza as pessoas para uma única forma de expressão, e que estará sempre aberta a uma criação, à arte - diria Sartre (1987) - e à negociação social e colaborativa de debates acerca do melhor caminho para a melhor convivialidade política.

Não está advogado, contudo, em Merleau-Ponty, que haja um princípio salvador da pessoa de sua própria direção; e que lhe seja interno, seja de nascimento, ou civilizatório. Essas coisas se aprenderão na vida, na confecção de possibilidades abertas, e no risco. E a vida para Merleau-Ponty não está a salvo, nem por um princípio metafísico, nem por um princípio divino, nem por uma natureza sem contradição. Não há, por isso, na fenomenologia um finalismo, nem para a pessoa, nem para a História! Mais do que nunca o teor político- educacional terá que ser fruto de cuidado político. Não haverá estatuto prévio que nos defenda de nós mesmos. Não há um finalismo histórico. Não há uma teleologia prévia que não passe pela construção dos dramas da história. E não há história feita sem pessoas. As pessoas não são previsíveis por seu corpo próprio, que dá ou não substância às formas de intervenção, que tem reverberação nas políticas da sociedade global e para o destino de todas as criaturas. Não há estágios, nem nos processos desenvolvimento de uma criança, nem nos processos educacionais e sociopolíticos. Há, sim, uma tarefa aberta a todos e todas, e a necessidade de confecção carinhosa de teceduras de redes que organizem uma ação para a liberdade e autonomia. Só a partir de cada ser inteiro e vivo há sentido para se falar em liberdade. Liberdade não na acepção de adquirido doméstico ou no congelamento em estado de latência e repouso, mas a liberdade como expressão, na conflitividade, de um caminho radical em favor da melhor vida de tudo e todos e todas. É nesse sentido que o termo pessoa, na obra "O Personalismo", traz novidades expressas, o sentido que lhe dá Mounier (2004) o de a-frontar; isso é, dizer a que se veio! Pessoa não é um ser meloso, se forma na dramaticidade de uma luta pela vida e pela felicidade geral.

\footnotetext{
${ }^{12}$ Um impressionante exemplo da impossibilidade de definirmos caminhos onde há vitalidade própria: https://www.facebook.com/photo.php?v=10201496540688138\&set=vb.1614903219\&type=2\&theater
} 
A fenomenologia é tocada por uma visão holística, não como uma organização cosmética, idealizada do mundo, da história e dos sujeitos - sabe que terá uma posição em face da experiência viva do mundo -, mas não a imporá, contudo não calará seus pressupostos, compartilhando a cada pessoa, - não somente aos intelectuais ou quadros de direção; não somente à burguesia ou membros dos aparatos de inteligência e intervenção - dialogando, antes, com aqueles e aquelas que, desprotegidos, vulneráveis, sabem na pele o preço da existência, do sentido e do valor do que lhes sobra: a vida nua dos direitos (AGAMBEN, 2008).

Exatamente lá, onde a lógica da força, do poder, do desenvolvimento, das elites enquadradoras, dos conceitos de Ordem, de prescrição legal estiverem mais presentes, muito mais longe deles estará a verdade, que, segundo nosso poeta maior Thiago de Mello, "será servida antes da sobremesa". É necessário, como nunca, dizer que a Paz verdadeira, duradoura, justa, festiva e lutadora não está no lugar da disputa do poder pelo poder, nem na disputa das inteligências, nem na lógica das elites, muito além dos aparelhos de estado, e das lógicas do poder econômico. O Estado que temos não é o Estado que queremos, cujo fundamento, rigorosamente, é cada um de nós. A Paz sempre estará do lado menos ruidoso, muito mais lá onde a vida gratuita emerge como milagre, não se encobre com quinquilharias e cosméticos, não se maquia ou falsifica. Aninha-se onde há grandeza, dignidade e tolerância que lhe serão o principal tempero nos pratos das ações de convivialidade, de expressão de doação, de comunicação viva, na liberdade pessoal do silêncio, e no reconhecimento, até o fim das diferenças: diferença que resiste, não cala, se organiza, denuncia e luta esperançando. Anuncia e denuncia, uma paz que se modela na coragem da vontade de viver contra todos os ardis da morte.

\section{Referências}

AGAMBEN, G. O que resta de Auschwitz. O arquivo e a testemunha. São Paulo: Boitempo, 2008.(Homo Sacer III).

BUBER, M. Eu e tu.Introdução, notas e trad. Newton Aquiles von Zuben. São Paulo: Centauro, 2009.

BUEY, F.F. Marx e os marxismos. Uma reflexão para o século XXI. Trad. Simone Rezende da Silva. In: BORON, A.A.; AMADEO, J. GONZALEZ, S. (Orgs.). A teoria marxista hoje. Problemas e perspectivas. Buenos Aires: Red de Bibliotecas Virtuales de Ciencias Sociales de America Latina y el Caribe, de La Red de Centros Miembros de Clacso, 2007. Disponível em: $\langle$ http://bibliotecavirtual.clacso.org.ar/ar/libros/campus/marxispt/cap. 7.doc >. Acesso em: 23 abr. 2014.

CABRAL, C.A. Anotações sobre Merleau-Ponty. Textos de Estudos do GEMPO, Inédito. PPGE/UFMT, Maio/1914.

CAPALBO, C. A filosofia de Merleau-Ponty. Historicidade e ontologia. Londrina: Edições Humanidades, 2004.

CAPALBO. C. Fenomenologia e Ciências Humanas. Campinas: Ideias e Letras, 2008.

CHAUÍ, M. Experiência do Pensamento. Ensaios sobre a obra de Merleau-Ponty. São Paulo: Martins Fontes, 2002. 
DELEUZE, G. Crítica e clínica. São Paulo: Editora 34, 1997.

DUSSEL, E. Ética da libertação: na idade da globalização e da exclusão. Trad. Ephraim F. Alves, Jaime A. Clasen, Lucia M. E. Orth. Petrópolis: Vozes, 2000.

FREIRE, P. Pedagogia da autonomia: saberes necessários à prática educativa. 15ed. São Paulo: Paz e Terra, 2000.

FREIRE, P. Pedagogia do oprimido. Rio de Janeiro: Paz e Terra, 1968.

GEERTZ, C. A interpretação das culturas. Rio de Janeiro: Editora Guanabara, 1989.

GUTIERREZ, G. Pensamentos de Gustavo Gutierrez. In: Portal e-Jesus. Disponível em: <http://www.ejesus.com.br/gustavo-gutierrez-merino>. Acesso em 28 mai. 2014.

HUSSERL, E. Investigações lógicas: sexta investigação - elementos de uma elucidação fenomenológica do conhecimento / Edmund Husserl. Trad. Zeljko Loparic, Andrea Maria Altino de Campos Loparic. São Paulo: Nova Cultural, 1996.

MELLO, T. Os estatutos do homem. In: Portal Rede Brasil de Direitos Humanos. Disponível em: <http://www.dhnet.org.br/desejos/textos/thmelo.htm>. Acesso em: 28 mai 2014.

MERLEAU-PONTY, M. Fenomenologia da percepção. São Paulo: Martins Fontes, 2011.

MERLEAU-PONTY, M. O visível e o invisível. São Paulo: Perspectiva, 2012.

MERLEAU-PONTY, M. Psicologia e pedagogia da criança. São Paulo: Martins Fontes, 2006.

MERTON, T. Homem algum é uma ilha. 4ed. Rio de Janeiro: Agir, 1961.

MORIN, E. Os sete Saberes Necessários à Educação do Futuro. 3a. ed. São Paulo:Cortez; Brasília, UNESCO, 2001.

MOUNIER, E. O personalismo. Trad. Vinicius Eduardo Alves. São Paulo: Centauro, 2004.

PASSOS, L. A. A centralidade do tempo e da temporalidade para a educação. Revista de Educação Pública, Cuiabá, v. 14, n. 26, p.131-149, 2005.

SARTRE, J.P. O existencialismo é um humanismo. A imaginação. Questão do método. Trad. Rita Correia Guedes, Luiz Roberto Salinas Forte, Bento Prado Junior. 3ed São Paulo: Nova Cultural, 1987.

WITTGENSTEIN, L. Investigações filosóficas. Trad. José Carlos Bruni. 2ed. São Paulo: Abril Cultural, 1979. (Os Pensadores. Vol. 46). 